STUDY OF LIPID AND THYROID PROFILE IN EARLY MENOPAUSAL WOMEN IN DR. B.R.AMBEDKAR MEDICAL COLLEGE AND HOSPITAL.

\section{General Medicine}

Dr Rekha G*

\section{Dr Rajdeepak V S}

\section{Dr Satish L}

Assistant Professor, Department Of General Medicine, Sapthagiri Institute Of Medical Sciences And Research Center, Bengaluru, Karnataka, India. *Corresponding Author

Assistant Professor, Department Of General Medicine, Sapthagiri Institute Of Medical Sciences And Research Center, Bengaluru, Karnataka, India.

Consultant Interventional Cardiologist, Sparsh Hospital, Yeshwanthpura, Bengaluru, India.

\title{
ABSTRACT
}

INTRODUCTION: Menopause is a normal, natural event, defined as the final menstrual period (FMP). Women now spend one third to one half of their lives after menopause. Women who underwent natural menopause before age 45 years had an increased risk of thyroid dysfunction, diabetes, hypertension, obesity and dyslipidemia which are considered as risk factors for ischemic heart disease. METHODOLOGY: 50 early menopausal women attending the outpatient and inpatient departments of DR.B.R. Ambedkar Medical College and Hospital, were randomly included in this study. All the patients are subjected to detailed history regarding demographic data, general physical examination (including vitals, weight, height, BMI). Investigations like Thyroid profile (T3,T4,TSH), Fasting Lipid Profile, ECG were done. RESULTS: Study patients were found to be in 40-70 years age group, with maximum number of patients in 4050 years group. Mean age of menopause is $42.34 \pm 1.92$. Among the studied population $27(54 \%)$ patients had thyroid dysfunction. All 27 patients had hypothyroidism, 3(13\%) patients had subclinical hypothyroidism upon evaluation and rest of the patients were euthyroid. TSH was found to be higher $6.50 \pm 4.87$ among the studied patients and was found to be statistically associated with thyroid disorders. In studied subjects 19(38\%) had dyslipidemia, 1 patient had borderline and rest 30 patients had normal lipid profile. 17(34\%) of studied patients had ischemic heart disease. Among the 17 patients having IHD, 10(58.82\%) patients were hypothyroid, 15(88.23\%) patients had hypertension and $10(52.63 \%)$ had dyslipidemia. Amongst the studied subjects 33(66\%) patients were overweight and $9(18 \%)$ patients were obese according to BMI. CONCLUSION: Significant number of early menopausal women in this study have hypertension, thyroid dysfunction, dyslipidemia and high BMI which are considered as risk factors for coronary artery disease. Hence screening can be recommended for early menopausal women for thyroid dysfunction, especially in those with increasing age, duration of menopause and overweight women to evaluate and correct dyslipidemia so as to prevent adverse atherosclerotic cardiovascular complications and to prevent morbidity and mortality.

\section{KEYWORDS}

Menopause, Hypothyroidism, Dyslipidemia, Atherosclerosis, Coronary Artery Disease, Ischemic Heart Disease, Hypertension.

AIMAND OBJECTIVES OFTHE STUDY

- To study Lipid and Thyroid Profile in Early Menopausal Women.

- To Evaluate and Correct Dyslipidemia so as to Prevent Adverse Atherosclerotic Cardiovascular Complications and to Prevent Morbidity and Mortality.

\section{METHODS}

50 early menopausal women attending the outpatient and inpatient departments of DR.B.R.Ambedkar Medical College and Hospital, were randomly included in this study.

The present study was conducted during the period of October 2015 to September 2016. Prior to the commencement, the study was approved by the Ethical and Research Committee, Dr. B. R. Ambedkar Medical College, Bengaluru. All patients fulfilling selection criteria were explained about the purpose of study and a written informed consent was obtained before enrolment.

Women aged $<45$ years and not having menstrual cycles for about 12 consecutive months were included in the study.

Women aged more than >45years and who have undergone hysterectomy, bilateral oophorectomy, pelvic chemo-radiation for cancers, pregnantwomen were excluded from the study.

After detailed history taking regarding age at menopause and duration of menopause, general and systemic examination was done.

Following investigations were done to all subjects- Fasting lipid profile, fasting thyroid profile, Electrocardiogram.

The diagnostic criteria for dyslipidemia were taken as per NCEP, ATP III guidelines.

Total cholesterol $>/=200 \mathrm{mg} / \mathrm{dl}$

Triglycerides $>/=150 \mathrm{mg} / \mathrm{dl}$
HDL-C $<40 \mathrm{mg} / \mathrm{dl}$

LDL-C $>/=130 \mathrm{mg} / \mathrm{dl}$

Thyroid profile includes assessment of Thyroid stimulating hormone(TSH) and Serum total $\mathrm{T}_{4}$ and total $\mathrm{T}_{3}$ Any values beyond the normal reference values of Central laboratory of DrB R Ambedkar Medical college and hospital for particular age is considered as abnormal. Normal values for non-pregnant women are: (as per lab)

TSH $0.4-4 \mathrm{mIU} / \mathrm{ml}$

$\mathrm{T}_{3} 0.9-1.95 \mathrm{ng} / \mathrm{ml}$

$\mathrm{T}_{4} 4.4-12.5 \mathrm{mcg} / \mathrm{dl}$

12-lead Electrocardiogram was done atrest for all patients

BMI was calculated with formula:

$\mathrm{BMI}=$ weight $($ in $\mathrm{kg}) /$ height $^{2}$ (in meter)

Underweight: $<18.5 \mathrm{~kg} / \mathrm{m}^{2}$

Healthy weight: $18.5-24.9 \mathrm{~kg} / \mathrm{m}^{2}$

Overweight: $25.0-29.9 \mathrm{~kg} / \mathrm{m}^{2}$

Obesity: $>30 \mathrm{~kg} / \mathrm{m}^{2}$

Statistical Methods: Descriptive and inferential statistical analysis has been carried out in the present study. Results on continuous measurements are presented on Mean SD (Min-Max) and results on categorical measurements are presented in Number (\%). Significance is assessed at $5 \%$ level of significance.

The following assumptions on data are made,

Assumptions:

1. Dependent variables should be normally distributed,

2. Samples drawn from the population should be random, Cases of the samples should be independent.

Analysis of variance (ANOVA) has been used to find the significance of study parameters between three or more groups of patients, Student $t$ test ( two tailed, independent) has been used to find the significance of study parameters on continuous scale between two groups (Inter group analysis) on metric parameters. 


\section{Significant figure}

+ Suggestive significance (Pvalue: $0.05<P<0.10$ )

* Moderately significant (Pvalue:0.01<P 0.05)

** Strongly significant (Pvalue: P0.01)

\section{RESULTS}

The clinical data for present study was collected from 50 early menopausal women attending inpatient and outpatient departments of Dr B. R. Ambedkar Medical College and Hospital, Bengaluru from October 2015 to September 2016.

Study patients were found to be in the age group of 40-70 years , with maximum number of patients in 40-50years age group. Mean age of patients in study was $52.80 \pm 7.38$

Age of menopause of the study patients was $<45$ years with maximum number of patients $48(96 \%)$ attained menopause between $40-45$ years and $2(4 \%)$ attained menopause $<40$ years. Mean age of menopause is $42.34 \pm 1.92$

Among the 50 studied patients $41(82 \%)$ were hypertensive. Rest 9 (18) patients were normotensive.(Table 1)

Table 1: Prevalence of Hypertension

\begin{tabular}{|l|c|c|}
\hline H/O Hypertension & No. of patients $(\mathbf{n}=\mathbf{5 0})$ & $\mathbf{\%}$ \\
\hline No & 9 & 18.0 \\
\hline Yes & 41 & 82.0 \\
\hline$\bullet \quad \leq 1$ & 6 & 12.0 \\
\hline$\cdot \quad 1-2$ & 14 & 28.0 \\
\hline$\cdot \quad 2-5$ & 7 & 14.0 \\
\hline$\cdot \quad>5$ & 14 & 28.0 \\
\hline
\end{tabular}

$27(54 \%)$ patients had thyroid dysfunction. All 27 patients had hypothyroidism, $3(6 \%)$ patients had subclinical hypothyroidism and $20(40 \%)$ patients were euthyroid. Among the clinical variables studied in relation with thyroid disorders, Age of menopause was associated with thyroid dysfunction and was statistically significant.

$19(38 \%)$ patients had dyslipidemia, 30(60\%) patients had normal lipid profile values. $1(2 \%)$ patient had borderline dyslipidemia. Among the lipid parameters studied in study subjects, triglyceride levels was statistically associated with thyroid disorders.(Table 2)

Table 2: Comparison of Lipid parameters in relation to Thyroid dysfunction

\begin{tabular}{|c|c|c|c|c|}
\hline \multirow{2}{*}{ Lipids } & \multicolumn{2}{|c|}{ Thyroid Disorders } & Total & $\begin{array}{c}\text { P } \\
\text { value }\end{array}$ \\
\cline { 2 - 3 } & Absent & Present & & \\
\hline $\begin{array}{c}\text { Total Cholesterol } \\
(\mathrm{mg} / \mathrm{dl})\end{array}$ & $203.13 \pm 43.91$ & $204.19 \pm 45.13$ & $203.7 \pm 44.12$ & 0.934 \\
\hline TGL $(\mathrm{mg} / \mathrm{dl})$ & $202.26 \pm 105.96$ & $156.52 \pm 50.06$ & $177.56 \pm 83.07$ & $0.051 *$ \\
\hline LDL (mg/dl) & $134.70 \pm 37.10$ & $124.22 \pm 31.13$ & $129.04 \pm 34.06$ & 0.283 \\
\hline HDL (mg/dl) & $44.65 \pm 5.60$ & $45.79 \pm 8.84$ & $45.27 \pm 7.47$ & 0.596 \\
\hline
\end{tabular}

On physical evaluation $8(16 \%)$ were found to have normal BMI. And 33(66\%) were overweight. 9(18\%) were obese.(Figure 1)

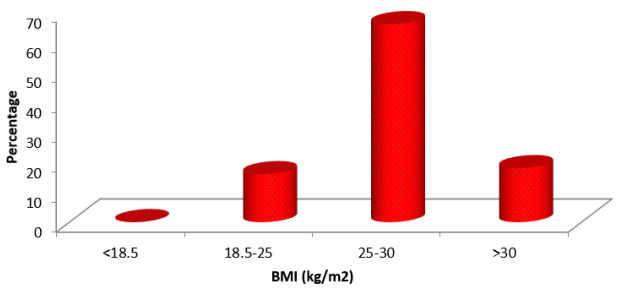

Figure 1: BMI $\left(\mathrm{kg} / \mathrm{m}^{2}\right)$ distribution

Out of 50 patients studied $17(34 \%)$ of had ischemic heart disease and $33(66 \%)$ patients had no IHD.(Figure 2$)$.

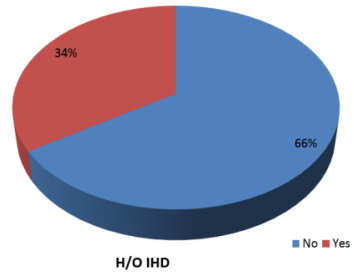

Figure 2: Distribution of Ischemic heart disease
Among the 17 patients who had ischemic heart disease, 1 patient had Anteroseptal Myocardial Infarction, 1 had Atrial fibrillation, 2 had Inferior wall Myocardial infarction, and 13 patients had old Ischemic heart disease changes.

Among 50 early menopausal women 17(34\%) patients had Ischemic heart disease. $10(58.82 \%)$ patients were hypothyroid, $15(88.23 \%)$ patients had hypertension and $10(52.63 \%)$ had dyslipidemia.

\section{DISCUSSION}

The present study was done on 50 early menopausal women attending as outpatient and inpatients in the Department of General Medicine, Dr. B.R.Ambedkar medical college and hospital. All patients are screened for thyroid dysfunction, dyslipidemia.

Study patients were found to be in 40-70 years age group, with maximum in number of patient in 40-50years group. Mean age of patients in study was 52.80土7.38. Age of menopause of the study patients was $<45$ years with maximum number of patients attained menopause between $40-45$ years. Mean age of menopause is $42.34 \pm 1.92$. Duration of menopause among the study population was between 1-25 years, with maximum number of patients are between $11-15$ years $(28 \%)$.Among the studied patients $41(82 \%)$ were hypertensive. In NHANES III, the rate of rise in SBP tended to be steeper in postmenopausal compared with premenopausal women. Staessen ${ }^{1}$ and associates reported that even after adjustment for age and body mass index, postmenopausal women are more than twice as likely to have hypertension as premenopausal women. Among the studied population 27(54\%) patients had thyroid dysfunction. All 27 patients had hypothyroidism. Among remaining 23 patients, 3(13\%) patients had subclinical hypothyroidism and rest of the patients were euthyroid. The prevalence of subclinical hypothyroidism in the US population is about $4 \%$ to $8.5 \%$ in those without known thyroid disease. The prevalence increases with age. There is also a correlation seen between duration of menopause and thyroid dysfunction with maximum hypothyroid patients having more than 10 years of menopause. The thyroid menopause connection is complex. It actually stems from close interactions between hormones the thyroid produces and the reproductive organs. Because hormones produced by the thyroid regulate metabolism, they directly influence the activity of reproductive glands. TSH was found to be higher $6.50 \pm 4.87$ among the studied patients and was found to be statistically associated with thyroid disorders. Among the studied population, $19(38 \%)$ had dyslipidemia. Remaining 30(60\%) patients were normal. Among the lipid parameters studied majority of the patient had high total cholesterol, triglyceride and LDL . On comparing the lipid parameters with the thyroid dysfunction, among the lipid parameters studied, triglyceride levels was statistically associated with thyroid disorders. Both the Los Angeles Atherosclerosis Study and the SWAN Heart Women demonstrated that the anti-atherogenic effect of HDL diminishes in women around the age of menopause $e^{2,3}$ and it was suggested that it is possibly related to changes in the lipoprotein subclass profile observed during the menopausal transition. Among the patient studied $8(16 \%)$ were found to have normal BMI. And $33(66 \%)$ were overweight. $9(18 \%)$ were obese. $17(34 \%)$ of studied patients had ischemic heart disease and remaining $33(66 \%)$ patients were normal. Among the 17 patients who had ischemic heart disease, 1 patient had Antero-septal Myocardial Infarction, 1 had Atrial fibrillation, 2 had Inferior wall Myocardial infarction, and 13 patients had old Ischemic heart disease changes on the ECG. MESA(Multi-ethnic study of atherosclerosis) showed that there was an 1.5-2 fold increase in CHD mortality in women with menopause at early age $(<45$ years $)$ versus those with menopause at more average age $(>49$ years $)$. Early natural menopause (40-44 v/s 50-54years) and MI were significantly related (relative risk, 1.42;95\% VCI, 1.08-1.86). ${ }^{4}$ Among 50 early menopausal women $17(34 \%)$ patients had Ischemic heart disease. All $17(100 \%)$ patients were diabetic, $10(58.82 \%)$ patients were hypothyroid, $15(88.23 \%)$ patients had hypertension and 10 $(52.63 \%)$ had dyslipidemia. Gordon T, Kannel WB et $\mathrm{al}^{5}$. and Kannel WB, McGee DL et $\mathrm{al}^{6}$. studies supported that the risk factors for coronary artery disease have included blood pressure, cigarette smoking, raised total cholesterol (TC), LDL-C, low HDL-C, and diabetes. 


\section{CONCLUSION}

Women now spend one third to one half of their lives after menopause. Postmenopausal period are at higher risk of hypertension, pro-atherogenic lipid changes, diabetes mellitus and severe cardiovascular diseases compared to premenopausal counterparts. Women who underwent natural menopause before age 45 years had an increased risk of ischemic heart disease. Early menopause along with diabetes has a synergistic effect over the incidence of cardiovascular diseases and other illnesses. Hence screening can be recommended for early menopausal women for thyroid dysfunction, especially in those with increasing age, duration of menopause and overweightwomen to evaluate and correct dyslipidemia so as to prevent adverse atherosclerotic cardiovascular complications and to prevent morbidity and mortality. A larger study needs to be conducted in early menopausal women to evaluate these factors.

\section{DECLARATIONS}

Funding: Non-funded

Conflict of interest: None

Ethical approval: Notrequired

\section{REFERENCES} 1. Staessen JA, Fagard R, Thijs L, et al. Randomised double-blind comparison of placebo
and active treatment for older patients with isolated systolic hypertension. The Systolic Hypertension in Europe (Syst-Eur) Trial Investigators. Lancet 350: 757-764, 1997.

2. Fan AZ, Dwyer J. Sex differences in the relation of HDL cholesterol to progression of carotid intima-media thickness: the Los Angeles Atherosclerosis Study. Atherosclerosis 2007; 195: e191-196

3. Woodard GA, Brooks MM, Barinas-Mitchell E, et al. Lipids, menopause, and early atherosclerosis in Study of Women's Health Across the Nation Heart women. Menopause 2011; 18: 376-384.

4. Melissa Wellons, Pamela.J.Schreiner, David.M.Herrington, et al: Early menopause predicts future coronary heart disease and stroke- Multi-ethnic study of atherosclerosis predicts future coronary heart disease and stroke- Multi-ethnic stud
in USA-Menopause, Author Manuscript, Oct 2013,page 1081-1087.

5. Gordon T, Kannel WB. Multiple risk functions for predicting coronary heart disease: the Gordon T, Kannel WB. Multiple risk functions for predicting coronary
concept, accuracy, and application. Am Heart J 1982;103:1031-1039.

6. Kannel WB, McGee DL. Diabetes and glucose tolerance as risk factors for cardiovascular disease: the Framingham Study. Diabetes Care 1979;2:120-126. 